\title{
CHEWING EFFICIENCY AND MASSETER MUSCLE ACTIVITY OF CONVENTIONAL DENTURES, IMPLANT-SUPPORTED OVERDENTURES, AND FIXED HYBRID PROSTHESES IN PATIENTS WITH ATROPHIED MANDIBLES. A CROSS-OVER STUDY
}

\author{
Mohamed Elsayed Elgamal* and Osama Mohammed Raouf Askar
}

\begin{abstract}
Purpose: This crossover study evaluated masticatory efficiency and masseter muscle activity of conventional dentures, implant-assisted overdentures, and fixed hybrid prostheses in patients with atrophied mandibles.

Materials and methods: Twenty edentulous patients with mandibular ridge atrophy received mandibular and maxillary conventional dentures (control, CD). Following three months adaptation period, four parallel implants were installed in the interforaminal region. In a random method, bar overdentures (BOD) or fixed hybrid prosthesis (FHP) was constructed for each patient. Chewing efficiency (in terms of variance of the hue, $\mathrm{VOH}$ ) was estimated utilizing chewing gum and ViewGum software program. EMG of masseter muscles (in terms of amplitude) was completed while clenching without food and clenching on soft and hard foods or without food. Measurements were performed three months after wearing the following prostheses: $\mathrm{CD}, \mathrm{BOD}$, and FHP.
\end{abstract}

Results: BOD and FHP recorded significantly lower VOH than conventional dentures. No difference was found in VOH between BOD and FHP. The BOD and FHP exhibited significantly higher amplitude than the $\mathrm{CD}$ group. No significant differences amplitude between BOD and FHP prostheses were noted for all clenchings. Clenching on the hard food achieved the highest amplitude and clenching with no foods achieved the lowest amplitude.

Conclusion: Within the scope of this trial, it could be concluded that both fixed hybrid prosthesis (FHP) and long bar overdentures (BOD) supported by 4 parallel interforaminal implants with distal cantilevers up to first molar teeth are recommended treatment modalities in patients with atrophied mandibular ridges as both improved chewing efficiency and EMG compared conventional denture.

KEYWORDS: electromyographic activity, chewing efficiency, atrophied mandible, hybrid prosthesis, implant overdentures.

* Lecturer of Prosthodontics Department, Faculty of Dentistry, Mansoura University, Mansoura, Egypt. 


\section{INTRODUCTION}

Conventional dentures (CD) are associated with many problems in patients with severely resorbed mandibles due to an inadequate amount of retention and stability. Such problems include pain during mastication, low food taste and texture perception, reduced masticatory ability to chewing healthy vegetables and fruits, generalized weakness, and reduction in social contact due to embarrassment of wearing dentures ${ }^{1}$. Oral function is improved when the mandibular prosthesis was stabilized by osseointegrated implants due to increased electrical activity of the masseter muscles. Moreover, a regular chewing pattern, better mandibular border movements, reduction of pain during mastication improve usually improve patient satisfaction with implant-supported prosthesis compared with conventional complete dentures ${ }^{2-5}$

Due to the atrophy of the alveolar ridge of the mandible, dental implantation without bone grafting or nerve lateralization surgery is possible only in the interforaminal segment ${ }^{6}$. The insertion of the implants in the interforaminal region was associated with high success rate due to high bone density and location away from vital structures. ${ }^{7}$ One of the treatment options involves the placement of at least four implants in the interforaminal area parallel to each other to support fixed cantilevered screw-retained prosthesis or flanged implant-supported overdentures ${ }^{8}$. The concept of fullarch fixed hybrid prostheses supported by four or five implants with bilateral distal cantilevers in the molar region has been advocated originally by Brånemark for the restoration of the chewing function in patients with atrophied mandibles ${ }^{9}$. The posterior teeth in the hybrid prosthesis is lesser than a conventional complete denture and is retained by screws threaded into the implant abutments ${ }^{10}$. The concept was modified in the last 2 decades by using inclined posterior implants (to decrease the cantilever lengths) and immediate loading protocol $^{6,11}$. A common design for implant-supported overdentures is to splint the interforaminal implants by bar attachments with cantilevered bar segments to provide adequate support, retention, and stability and to minimize mucosal loading during mastication ${ }^{12}$. These overdentures are totally implantsupported and have clinical merits of the fixed prosthesis with the advantages of removable dentures ${ }^{8}$

The choice of implant-supported overdentures or fixed prostheses may be made according to several factors as; distribution and number of implants, configuration and morphology of residual ridge, hygiene protocol, cost, patient expectations, and esthetic result. ${ }^{13}$ Fixed prostheses are preferred when alveolar bone and soft tissue are not affected and the implants have adequate numbers and position. However, such restoration may be limited by increased cost and difficulty of managing prosthetic complications compared to removable overdentures ${ }^{14}$. The implant-supported overdentures are preferred in patients with mandibular bone atrophy to improve speech, enhance appearance by restoring lip support, reducing the length of crowns, and managing unfavorable jaw relationship ${ }^{15}$. Moreover, overdentures are cost-effective and can be removed at night to avoid bruxism ${ }^{16}$. Furthermore, prosthetic complications are easy to manage by adjusting or replacing retentive components ${ }^{17}$.

Reviewing the literature, some authors found no difference in patient satisfaction between implantsupported overdentures and screw-retained fixed prosthesis ${ }^{18,19}$. Other studies noted that patient satisfaction was improved with screw-retained fixed prosthesis..$^{20,21}$ Several studies reported improvement of EMG activity of muscles of mastication and chewing efficiency with the complete implant-supported prosthesis in comparison to conventional complete denture $^{22,23}$. Also, the effect of overdenture anchor type on EMG activity and chewing efficiency was investigated in other studies ${ }^{24,25}$. Elsyad et al. ${ }^{25}$ found that four implants distributed in the canine and first molar region and connected with bar attachments showed improved EMG activity and masticatory 
efficiency than two-implant overdentures ${ }^{25}$. Unfortunately, studies comparing conventional dentures, and 4-implant supported fixed and removable prosthesis using cross-over study design are still scarce. Only one study ${ }^{26}$ compared EMG muscle activity between the fixed prosthesis and long bar overdentures during chewing different types of food textures on five inter-foraminal implants ${ }^{26}$. The authors found that long-bar overdentures were efficient as the fixed prosthesis. This investigation aimed to evaluate, within-patient, the masticatory efficiency and masseter muscle EMG activity of conventional dentures (CD), implant-assisted bar overdentures (BOD), and fixed hybrid prostheses (FHP) in subjects with resorbed mandibles.

\section{MATERIAL AND METHODS}

\section{Participant selection and study design}

This prospective cross-over study was conducted on 20 edentulous patients (10 men /10 women, ages ranged between 45 and 65 years) who had persistent mandibular denture problems due to atrophy of mandibular ridges. All patients were recruited from the outpatient clinic of the Prosthodontic Department, Faculty of Dentistry, Mansoura University, Egypt. In this study, the sample size was selected according to the clinical findings in another crossover studies ${ }^{25,27}$ in which reported a significant difference in masticatory efficiency and masseter EMG activity between several types of mandibular prostheses. Sample size calculation was not conducted. All included patients had the following criteria; 1) Discomfort due to the looseness of mandibular dentures, 2) mandibular bone atrophy with adequate bone quantity to install implants with minimum $3.75 \mathrm{~mm}$ in diameter and $11 \mathrm{~mm}$ in length (class IV-VI according to Cawood, and Howell ${ }^{28}$ as verified by preoperative panoramic and cone-beam CT radiographs), 3) good bone quality (classes IIII according to Lekholm and Zarb ${ }^{29}$ ). The patients were rejected if they had; 1) systemic diseases that preclude implant surgery, 2) previous head and neck radiotherapy, 3 ) heavy smoking habit ( $>10$ cigarettes per day). Each participant received the following mandibular prostheses; conventional denture (CD), implant-supported overdentures with cantilevered bar attachment (BOD), and fixed cantilevered hybrid prosthesis (FHP). The patients signed consents that include all the steps of the study and the necessity for periodic recall visits throughout the whole research duration. The protocol was approved by the ethical committee of the Faculty.

\section{Surgical and prosthetic procedures}

New dentures fabricated with the balanced occlusal scheme using semi-anatomic acrylic teeth were delivered to all participants. The participants were instructed to use the dentures for three months before implant placement to promote satisfactory neuromuscular control. Then chewing efficiency and EMG were estimated for the conventional complete denture (CD group). The mandibular denture was duplicated using clear heat-cured acrylic resin to be used as a radiographic template after the addition of radiopaque gutta-percha markers in the proposed implant positions (lateral incisor and first premolar areas). All participants administrated prophylactic antibiotics one day before implant placement and continued 7 days after surgery. Participants were asked to rinse their mouth with chlorhexidine mouthwash just before surgery and 7 days after surgery. Four parallel implants (TioLogic, Dentaurum) were inserted in the inter-foraminal area using the conventional submerged surgical approach and conventional loading protocol. Implants were installed by the same surgeon with a minimum torque of $35 \mathrm{Ncm}$ to give high initial stability. Relief was done in the mandibular denture over the implants and tissue conditioner (Visco-gel; DENTSPLY, Weybridge, UK) was used as a relining material. Following osseointegration duration, an open tray fixture level impression technique was performed using long transfer copings after splinting 
the copings with wire and auto polymerized resin (Duralay, Reliance Dental, Alsip, USA) to avoid movement during impression removal. The implant analogs were connected to the copings and the impression was poured.

To eliminate the effect of the order of implantsupported restoration on measurements, the patients were divided into 2 sets using randomly generated numbers created in an Excel spreadsheet. The first set included 10 patients (5 males and 5 females) who received BOD first, then after 3 months of adaptation, chewing efficiency and EMG activity were measured. One month washout period to eliminate carryover effects was planned during which BOD was removed, healing abutments were connected and CD was relined. FHP was delivered to the patients and after 3 months of adaptation, the measurements were repeated. The second set included 10 patients (5 males and 5 females) who received FHP first, then after 3 months of adaptation, masticatory efficiency and muscle activity were measured. After the washout period, BOD was delivered to the patients and after 3 months of adaptation, the measurements were repeated.

For BOD prosthesis, plastic caps were screwed to bar abutments. Dolder bar joint plastic pattern (Dolder bar joint, Dentaurum) was lute to the caps with about $12 \mathrm{~mm}$ distal cantilevers to reach the area of mandibular first molars ${ }^{30,31}$. A 1-1.5 mm clearance space was kept between the ridge and the bar for cleaning. The plastic bar was cast into cobaltchromium and and tried intraorally using Sheffield single screw test to check passivity (fig 1,a). Titanium Dolder bar clips were fastened over the bar before processing of acrylic resin (fig $\mathbf{1} \mathbf{b \&} \mathbf{c}$ ). For fixed hybrid prosthesis (FHP), the participants received screw-retained PFM (Porcelain Fused to Metal) cantilevered prosthesis that replaces both
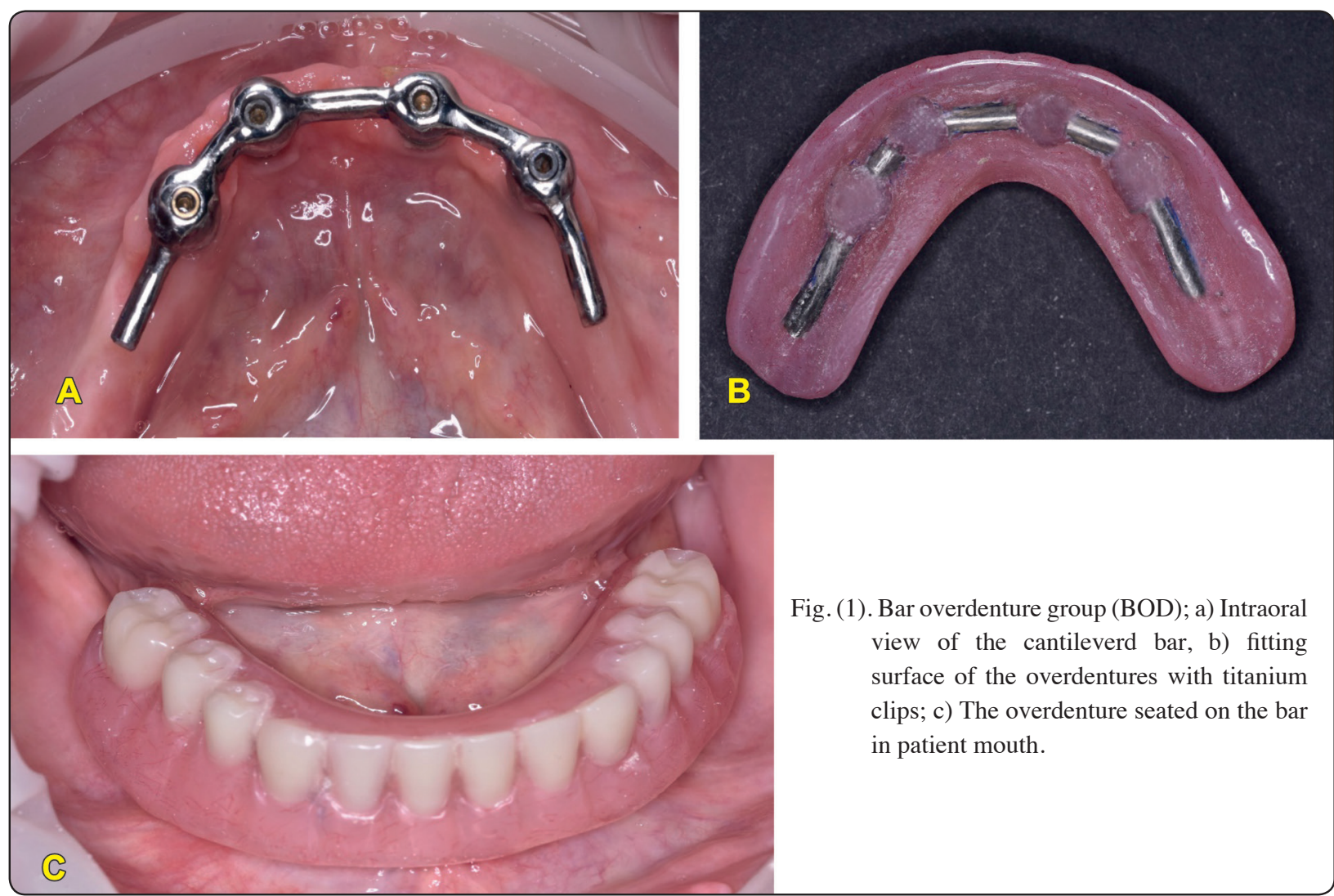

Fig. (1). Bar overdenture group (BOD); a) Intraoral view of the cantileverd bar, b) fitting surface of the overdentures with titanium clips; c) The overdenture seated on the bar in patient mouth. 
gingival tissues with pink porcelain and missing teeth up to the first molar areas with $12 \mathrm{~mm}$ distal cantilevers ${ }^{30,31}$. Four multiunit abutments (Dentaurum) were screwed to the implant analogs. A digital model was made by scanning the master cast using a 3D scanner (Amann Girrbach AG. Koblach). The final prosthesis framework was planned virtually utilizing its software, printed using prototyping technology, and tried in intraorally for passivity using the single screw test. The resin framework was cast using cobalt-chromium alloy (BEGO Bremer) (fig 2,a). Opaque layer was added over the metal framework then the porcelain powder with different shades including the gingival tissues (IVOCLAR CLASSIC, Vivadent AG, FL-9494 Schaan, Liechtenstein) were mixed with modeling liquid and added layer by layer to contour the teeth and gingiva then finally fired, and glazed (fig $\mathbf{2 , b}$ ). The screw channels were closed using composite resin to prevent food ingress.

\section{Assessment of chewing efficiency}

The chewing efficiency was evaluated by a twocolor mixing ability test following the technique illustrated by Schimmel et al. ${ }^{32}$ utilizing Vivident Fruitswing chewing gum. Five gums samples prepared from two colored gums "Karpuz/Asai Üzümü" (gum3, Perfetti van Melle, Turkey): one with green color and the other with violet color were used in the chewing efficiency test. Patients were instructed to chew each sample (the violet side facing the palate) on their favored chewing side for 20 cycles. After chewing, the samples were prepared and labeled with random numbers (fig. 3). Both sides of the samples were scanned. The compound images were then evaluated with ViewGum software (dHAL Software, Greece). The software semiautomatically calibrate the hue value for each pixel after segmenting the image. Chewing efficiency was calculated using the variance of the hue ( $\mathrm{VOH})$ for each sample and the mean $\mathrm{VOH}$ for the 5 samples was subjected to statistical analysis. Good chewing efficiency produces more color mixing and less $(\mathrm{VOH})$ which is considered as the scale of mixing ${ }^{33}$.

\section{Evaluation of EMG activity of masseter muscle}

During EMG evaluation of the masseter muscles, the patients were instructed to set in an office-type chair with their head unsupported, arms beside the body, and hands on top of the thighs and maintain a naturally erect position. Two surface electrodes (away from each other by $15 \mathrm{~mm}$ ) were fixed to parallel to the fibers of the superficial belly of the masseter muscle with adhesive tape (fig 4 a\&b).The electrodes were connected to an EMG device (Nihon Kohden Corp, auto MUP detection, auto turns/amp analysis, and 2/4 channel compact

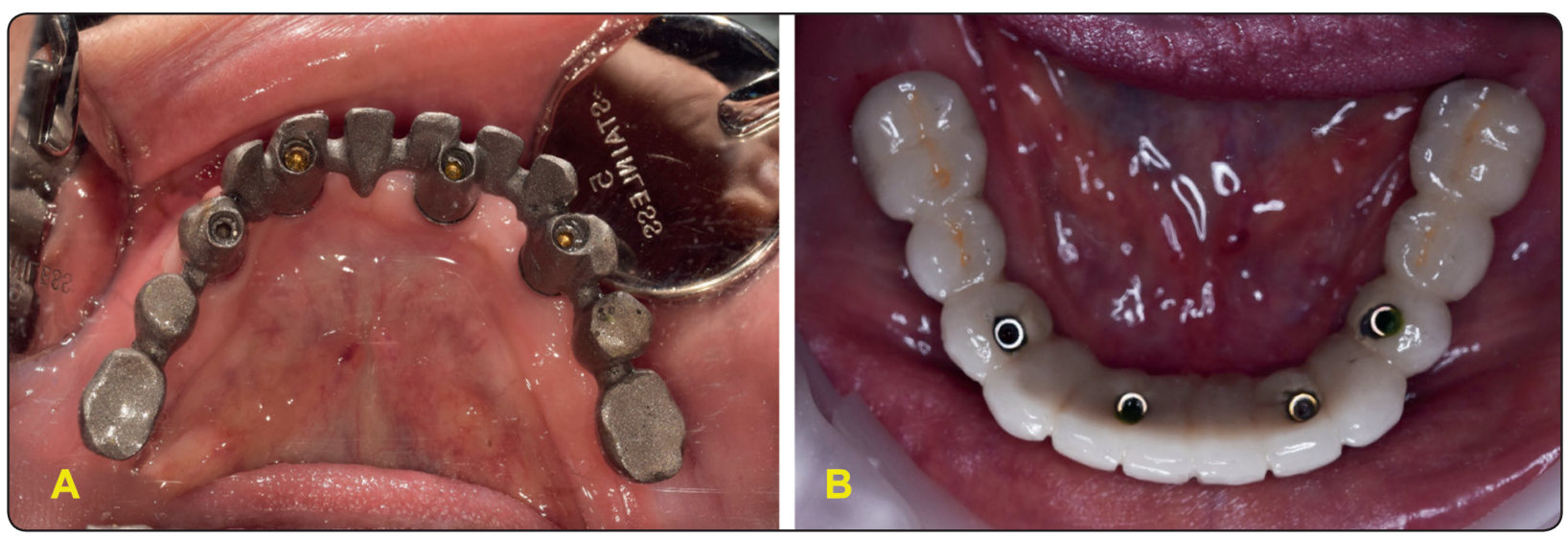

Fig. (2). Fixed hybrid group (FHP), a) try in of the metal framework in patient mouth, b) occlusal view of the fixed prostheis 


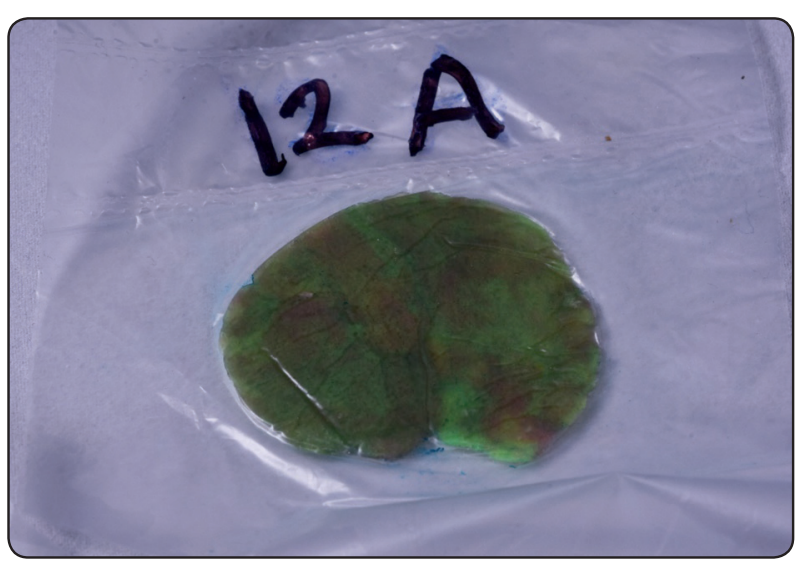

Fig 3. Chewed gum sample

low-noise amplifier). The assessment was made while maximum voluntary clenching (MVC) without food, clenching on hard food (carrot), and clenching on soft food (cake) to determine the effect of the existence of food and food type on EMG of masseter muscles. For each situation, the amplitude (EMG in $\mu$ Volt) of the left and right masseter muscles (EMG) were measured. EMG signals were recorded during clenching (with or without food) for $5 \mathrm{sec}$ (fig 4, c). Testing for each type of food was separated by a 2-minutes resting period to avoid muscle fatigue. For each food type, the measurements of the right and left sides were averaged as no significant difference between both sides was noted. Each test was repeated five times and the mean was used in statistical analysis.

Chewing efficiency and EMG activity were evaluated for each prosthesis by one calibrated examiner who could not be blinded to treatment groups. To assess the repeatability of measurements, the participants were recalled on a different day to repeat the masticatory efficiency and EMG activity tests ${ }^{25}$

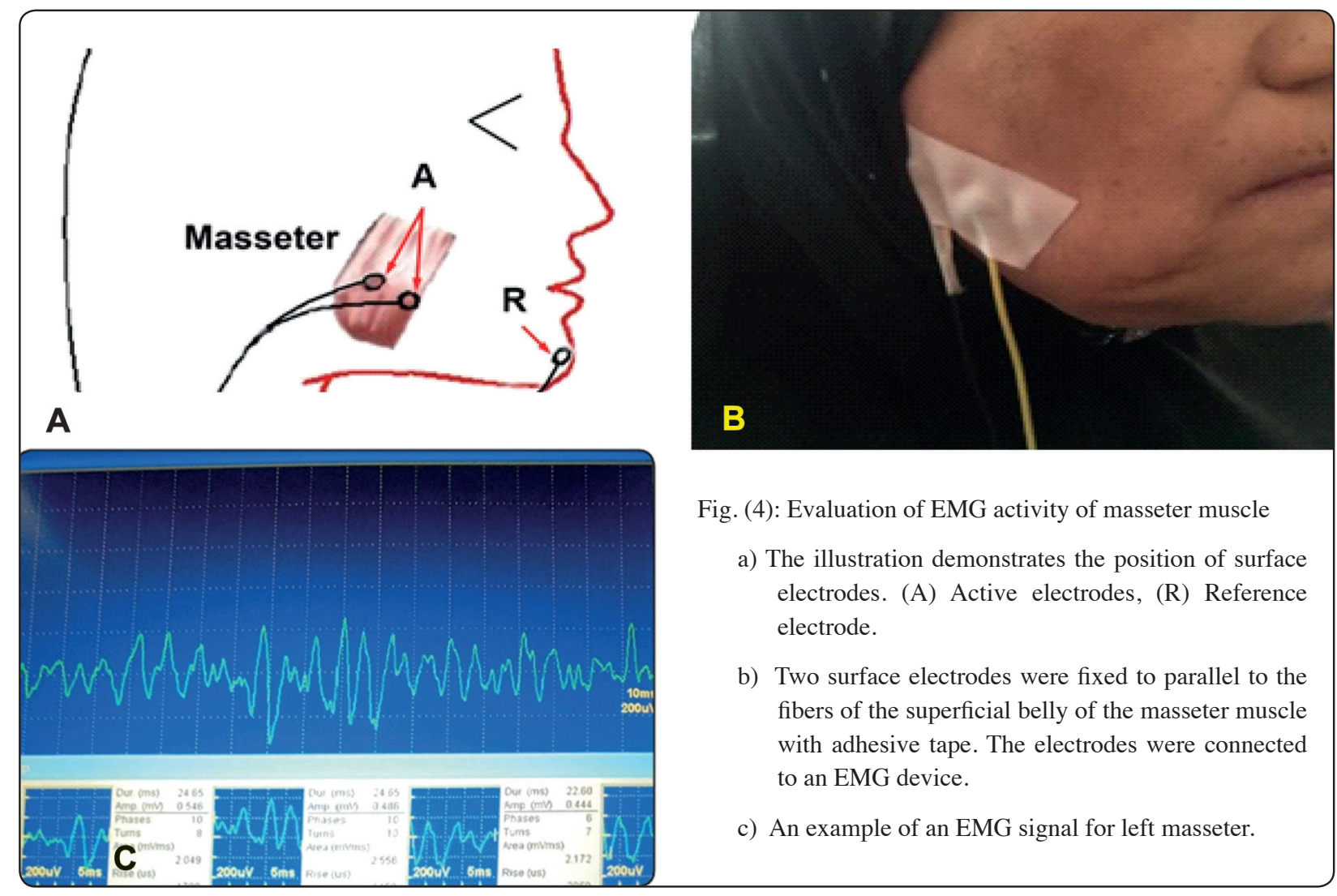




\section{Statistical analysis}

The data were analyzed using SPSS software version 22 (SPSS Inc., Chicago, IL, USA). Intraexaminer reliability was tested using the $\alpha$-Cronbach test. The Kruskal-Wallis test was used to compare $\mathrm{VOH}$ and amplitude ( $\mu$ Volt) values between different prostheses, Afterwards Dunn post hoc tests were used for comparisons between every 2 prostheses. To compare clenching situations for each prosthesis, the Freidman test was used, followed by Wilcoxon's test for pairwise comparisons. The level of significance was adjusted at $\mathrm{p}<.05$.

\section{RESULTS}

\section{Chewing efficiency}

The VOH data was reliable between measurements of the same examiner (correlation coefficient $>.80$ ). The mean $\mathrm{VOH}$ of $\mathrm{CD}, \mathrm{BOD}$, and FHP with 20 chewing strokes are presented in Table 1. A difference was observed in $\mathrm{VOH}$ among the three restorations $(\mathrm{p}=0.001)$. The $\mathrm{CD}$ exhibited the highest mean $\mathrm{VOH}$ value, then $\mathrm{BOD}$, and the FHP revealed the lowest mean $\mathrm{VOH}$ value. Implantsupported prosthesis (BOD and FHP) recorded significantly lower $\mathrm{VOH}$ than conventional complete denture (CD). VOH did not differ significantly between BOD and FHP.

\section{Electromyographic activity}

The masseter muscle EMG for all tested restorations while clenching with and without foods are presented in Table 2. The FHP demonestrated the highest amplitude, then BOD, and the CD displayed the lowest amplitude. There was a significant difference between the three prostheses during clenching without food $(\mathrm{p}=.001)$, clenching soft food $(\mathrm{p}=.008)$, and clenching hard food $(\mathrm{p}=$ .007). The BOD and FHP exhibited significantly higher amplitude than the CD group. No significant differences in EMG (amplitude) were noted between BOD and FHP prostheses for all clenching situations.

For all restorations, a significant difference between clenching situations (without food, with hard food, and with soft food) was found ( $\mathrm{P}=.001$ for $\mathrm{CD}, \mathrm{P}=.036$ for BOD, $\mathrm{P}=.009$ for FHP). Clenching hard food displayed the highest EMG (amplitude) and clenching with no food showed the lowest. Pairwise comparisons exhibited a significant difference in EMG between each 2 clenching situations $(\mathrm{p}<.05)$.

TABLE (1) Comparison of chewing efficiency (VOH) between different prostheses after 20 chewing strokes

\begin{tabular}{|c|c|c|c|c|c|c|}
\hline & \multirow{2}{*}{$C D n=10$} & \multirow{2}{*}{ BOD $n=10$} & \multirow{2}{*}{ FHP $n=10$} & \multicolumn{3}{|c|}{ Dunn tests } \\
\hline & & & & P1 & P2 & P3 \\
\hline $\mathbf{X} \pm$ SD & $0.5322 \pm 0.0021$ & $0.3746 \pm 0.0040$ & $0.3685 \pm 0.0026$ & & & \\
\hline Median & 0.5320 & 0.3750 & 0.3699 & $0.001 *$ & $0.001 *$ & 0.079 \\
\hline Min-Max & $0.5299-5351$ & $0.3699-0.3790$ & $0.3646-0.3711$ & & & \\
\hline Kruskal-Wallis & & $.001 *$ & & & & \\
\hline
\end{tabular}

$X$ : mean, SD; standard deviation, $P$; is significant at 5\%

P1: significance between $C D \& B O D$

P2: significance between $C D \&$ FHP

P3: significance between $\mathrm{BOD} \& \mathrm{FHP}$ 
TABLE (2) Comparison of average EMG activity (lVolt) of masseter muscles between different prostheses with different types of food.

\begin{tabular}{|c|c|c|c|c|c|}
\hline & & Clenching without food & Clenching on soft food & Clenching on hard food & Freidman test \\
\hline \multirow{3}{*}{ తి } & $\mathrm{X} \pm \mathrm{SD}$ & $81.8 \pm 3.5 \mathrm{a}$ & $101.5 \pm 7.1 \mathrm{~b}$ & $121.7 \pm 7.8 \mathrm{c}$ & \multirow{3}{*}{$0.001 *$} \\
\hline & Median & 82 & 101.3 & 123 & \\
\hline & Min-Max & $77-88$ & $90-111$ & $112-135$ & \\
\hline \multirow{3}{*}{ రิ } & $\mathrm{X} \pm \mathrm{SD}$ & $125 \pm 8.3 \mathrm{a}$ & $152.0 \pm 11.3 \mathrm{~b}$ & $181.0 \pm 11.2 \mathrm{c}$ & \multirow{3}{*}{$0.036^{*}$} \\
\hline & Median & 126 & 141 & 181 & \\
\hline & Min-Max & $120-149$ & $135-163$ & $161-201$ & \\
\hline \multirow{3}{*}{$\hat{I}$} & $\mathrm{X} \pm \mathrm{SD}$ & $132.6 \pm 10.3 \mathrm{a}$ & $164.0 \pm 12.8 \mathrm{~b}$ & $190.0 \pm 13.4 \mathrm{c}$ & \multirow{3}{*}{$0.009 *$} \\
\hline & Median & 132 & 155 & 190 & \\
\hline & Min-Max & $119-148$ & 149-176 & $170-211$ & \\
\hline \multicolumn{2}{|c|}{ Kruskal-Wallis test } & $\mathrm{P}=0.001^{*}$ & $\mathrm{P}=0.008^{*}$ & $\mathrm{P}=0.007^{*}$ & \\
\hline \multirow{3}{*}{\multicolumn{2}{|c|}{ Dunn test }} & $\mathrm{P} 1=.002 *$ & $\mathrm{P} 1=.004 *$ & $\mathrm{P} 1=.005$ & \\
\hline & & $\mathrm{P} 2=.001^{*}$ & $\mathrm{P} 2=.002 *$ & $\mathrm{P} 2=.001 *$ & \\
\hline & & $\mathrm{P} 3=.083$ & $\mathrm{P} 3=.12$ & $\mathrm{P} 3=.14$ & \\
\hline
\end{tabular}

$X:$ mean SD: standard deviation P:Probability*:significance $<0.05$

Different letters in the same raw showed a significant difference between each 2 clenching conditions

P1: significance between $C D \& B O D$.

P2: significance between $C D \&$ \&HP.

P3: significance between BOD \& FHP.

\section{DISCUSSION}

A self-controlled crossover study design was used as it allows within-patient comparison on a small sample of participants ${ }^{25}$. This design decreases the individual variation between patients (ie age, gender, muscle power, anatomical conditions of the jaws, and occlusion) than parallel-group studies when different treatment modalities are evaluated. Consequently, chewing efficiency and EMG measurements becomes more accurate and reliable. ${ }^{25,27}$ Optoelectronic colorimetric assessment was used for evaluation of chewing efficiency as it is considered as an accurate, discriminatory, and easy using tool especially after the introduction of ViewGum ${ }^{\circledR}$ software that facilitates semi-automatic visualization and calibration of the degree of color mixing between two different colored chewing gum specimens. Twenty chewing cycles were standardized for all groups as this number was considered enough for testing the mixing ability as recommended in other studies ${ }^{32,34}$ in which the authors found that 20 cycles are the most representative number of object mixing ability. Surface electromyography was used for masseter muscle activity as it is a widely accepted, safe, easy, non-invasive method in objective evaluation and quantification of the muscle energy in relation to various implant-supported prostheses ${ }^{4,35,36}$. In order to obtain accurate and consistent results during EMG measurements, the surface electrodes were positioned parallel to fibers of masseter muscle to 
allow receiving high and pure referenced electric activity. ${ }^{36}$

The chewing efficiency of implant-supported prostheses (BOD and FHP) was significantly higher than $\mathrm{CD}$. This may be related to the increased retention, stability, and support gained from implants which improved chewing efficiency and ability to mix the two colors of testing gums for each patient. The same observation was also noted in other studies ${ }^{25,27,37}$. The increased chewing efficiency with FHP and BOD compared to CD was in line with Muller et al..$^{38}$ who found that chewing efficiency with both implant-supported fixed prosthesis and implant overdentures was better than complete dentures but not as good as the dentate group

On the other hand, the reduced chewing efficiency with $\mathrm{CD}$ may be attributed to the pain that might occur during chewing and biting as a result of shifting and movement of the denture base. This movement caused increased pressure on the mucosa, especially with increased residual alveolar ridge resorption. ${ }^{27}$ The increased chewing efficiency with FHP than BOD, although not significant, may reflect the increased stability and retention obtained from screw-retained fixed prosthesis compared to bar attachments which in turn improves the muscle activity $^{4,24}$, increase bite forces ${ }^{39,40}$ and raise the capability of food comminution during mastication. This explanation concurs with the finding of CastilloOyague et $\mathrm{al}^{20}$ who found that fixed prostheses were associated with improved Oral Health-Related Quality of Life regarding pain and chewing ability compared with implant overdentures. The lack of significant difference in chewing efficiency between FHP and BOD was in agreement with the findings of Fein et al. ${ }^{26}$ who compared the masticatory function of fixed complete dentures and long bar implant overdentures on 5 or 6 implants by tracing mandibular movements during chewing of standardized test foods. They concluded that long-bar overdentures appear to be no less efficient than the fixed prosthesis in contrary to what was expected.
In this study, implant-supported FHP and BOD showed a significant EMG masseter muscle activity over CD. This was in agreement with the findings reported Jacobs \& van Steenberghe $(1993)^{41}$ found that muscle activity of two implants-bar overdentures and the implant-supported fixed prosthesis was higher than with $\mathrm{CD}$ group. They attributed the increased muscle activity to the increased support and stability of the implant-supported prosthesis that reestablished the muscle function. Similarly, de Rossi et al. ${ }^{42}$ found that All-on-Four maxillary and mandibular fixed prostheses and fully dentate patients had a similar EMG activity of masseter than temporalis muscles, which was significantly higher than patients wearing conventional dentures.

The increased muscle activity FHP and BOD compared to $\mathrm{CD}$ may be attributed to the presence of osseoperception in patients with implant prosthesis ${ }^{43}$ which improves tactile and stereognosis ability, and enhances masticatory function ${ }^{44}$. Also, the implants had a significant positive effect of implant treatment on maximum bite force, masticatory activity, and individual satisfaction compared to $\mathrm{CD}^{45}$. The improvement of muscle activity of implant-supported prosthesis may be due to enhancement of support, retention, and stability of the prostheses, creation of stable occlusal plane, improvement of oral perception, and increased patient comfort during chewing compared to conventional denture ${ }^{46,47}$. The reduced muscle activity with the conventional denture may be due to weakening of masticatory muscles results from chronic under-use of such muscles due to dentures instability ${ }^{48}$.

In our study, no significant difference in masseter muscle activity between FHP or BOD was found. This observation was in agreement with the study of Jacobs \& van Steenberghe ${ }^{49}$ who found no significant difference in muscle activity of patients rehabilitated by means of overdenture (on two or four implants connected by a bar) or patients rehabilitated with an implant-supported fixed prosthesis on four to six implants in either the maxilla or the mandible. Similarly, several studies ${ }^{42,50-52}$ compared 2-implant 
overdentures or 4-implant supported fixed prosthesis to dentate control subjects. The results revealed a general increase in the EMG-parameters that approached the values for normal dentate subjects and maintained this level over a long period.

The EMG activity of the masseter muscle was increased during clenching on food (either soft or hard) compared to clenching without food. This may be attributed to the need for more muscle energy to cut and grind foods. The increased muscle activity when clenching hard food compared to soft food was in line with several studies ${ }^{26,53,54}$ who showed a significant increase of EMG activity with an increase in food hardness. This may be attributed to the modulation of the contraction mechanisms through information from intra-oral receptors. The reduction of tactile sensation or proprioception feedback due to loss of periodontal ligament related to teeth extraction in total implantsupported prostheses may play a role in sensing and controlling the maximum biting force exerted on hard food objects and in turn increased muscle activity measured by EMG. ${ }^{2,25}$

We should acknowledge the small sample size and short-term follow-up as a limitation in this study. Therefore, a platform for future clinical research with larger cohorts and long-term follow-up is recommended to assess the EMG and masticatory function of various implant-supported prostheses particularly in patients with highly resorbed mandibular ridges.

\section{CONCLUSION}

Within the limitations of this study, it could be concluded that both fixed hybrid prosthesis (FHP) and long bar overdentures (BOD) supported by 4 parallel interforaminal implants with distal cantilevers up to first molar teeth are recommended treatment modalities in patients with atrophied mandibular ridges as both improved chewing efficiency and EMG compared conventional denture.

\section{REFERENCES}

1. Goodacre CJ, Goodacre BJ. Fixed vs removable complete arch implant prostheses: A literature review of prosthodontic outcomes. Eur J Oral Implantol 2017; 10: 13-34.

2. ELsyad M, El-Asfahani I, Kortam S, Mourad S. Masseter muscle activity of conventional denture, fixed prosthesis, and milled bar overdenture used for All-on-4 implant rehabilitation: A within-subject study. Clin Implant Dent Relat Res 2021; 23: 408-416.

3. Mohamed S. Electromyographic evaluation of the masseter and temporalis muscles activity in patients with complete denture, implant supported and implant retained mandibular overdentures. a cross-over study. Egypt. Dent. J 2021;67:699-709.

4. Afrashtehfar KI, Schimmel M.Muscular activity may improve in edentulous patients after implant treatment. Evid Based Dent 2016;17:119-120.

5. Dellavia C, Rosati R, Del Fabbro M, Pellegrini G. Functional jaw muscle assessment in patients with a full fixed prosthesis on a limited number of implants: a review of the literature. .Eur J Oral Implantol 2014;7:155-69.

6. Malo P, Rangert B, Nobre M. "All-on-Four" immediatefunction concept with Branemark System implants for completely edentulous mandibles: a retrospective clinical study. Clin Implant Dent Relat Res 2003; 5 Suppl 1: 2-9.

7. Moraschini V, Velloso G, Luz D, Cavalcante DM, dos Santos Porto Barboza E. Fixed rehabilitation of edentulous mandibles using 2 to four-implants: A systematic review. Imp Dent 2016;25 : 435-444.

8. Sadowsky SJ, Hansen PW. Evidence-based criteria for differential treatment planning of implant restorations for the mandibular edentulous patient. J Prosthodont 2014; 23: 104-111.

9. Branemark. I, Zarb. G, Albrektsson. T. Tissue Integrated Prostheses. Chicago, Quintessence 1985: pp 51-70, 117 I128.

10. Jain AR, Nallaswamy D, Ariga P, Philip JM. Full mouth rehabilitation of a patient with mandibular implant screw retained $\mathrm{Fp}-3$ prosthesis opposing maxillary acrylic removable over-denture. Contemp Clin Dent 2013; 4: 231-235.

11. Malo P, Rangert B, Nobre M. All-on-4 immediate-function concept with Branemark System implants for completely edentulous maxillae: a 1-year retrospective clinical study. Clin Implant Dent Relat Res 2005; 7 Suppl 1: S88-94. 
12. Raghoebar GM, Meijer HJ, Slot W, Slater JJ, Vissink A. A. systematic review of implant-supported overdentures in the edentulous maxilla, compared to the mandible: how many implants? Eur J Oral Implantol 2014; $:$ :191-201.

13. Payne GT, Zarb G. Prosthodontic Treatment for Edentulous Patients: Complete Dentures and Implant-Supported Prosthesis. In: Zarb GA BC, Eckert S, Jacob R, Fenton A, Mericske-Sterns, ed. Proceedings of the Implant overdentures.: Mosby, 2013: 330-339.

14. Beikler T, Flemmig TF. EAO consensus conference: economic evaluation of implant-supported prostheses. Clin Oral Implants Res 2015; 26 Suppl 11: 57-63.

15. de Jong MH, Wright PS, Meijer HJ, Tymstra N. Posterior mandibular residual ridge resorption in patients with overdentures supported by two or four endosseous implants in a 10-year prospective comparative study. Int J Oral Maxillofac Implants 2010; 25: 1168-1174.

16. Zitzmann NU, Marinello CP, Sendi P. A cost-effectiveness analysis of implant overdentures. J Dent Res 2006; 85: 717-721.

17. Katsoulis J, Brunner A, Mericske-Stern R. Maintenance of implant-supported maxillary prostheses: a 2-year controlled clinical trial. Int J Oral Maxillofac Implants 2011; 26: 648-656.

18. Oh SH, Kim Y, Park JY, Jung YJ, Kim SK, Park SY. Comparison of fixed implant-supported prostheses, removable implant-supported prostheses, and complete dentures: patient satisfaction and oral health-related quality of life. Clin Oral Implants Res 2016; 27: e31-37.

19. ELsyad MA, Elgamal M, Mohammed Askar O, Youssef Al-Tonbary G. Patient satisfaction and oral health-related quality of life (OHRQoL) of conventional denture, fixed prosthesis and milled bar overdenture for All-on-4 implant rehabilitation. A crossover study. Clin Oral Implants Res 2019;30:1107-1117.

20. Castillo-Oyague R, Suarez-Garcia MJ, Perea C, Rio JD, Lynch CD, Gonzalo E, Torres-Lagares D, Preciado A. Validation of a new, specific, complete, and short OHRQoL scale (QoLFAST-10) for wearers of implant overdentures and fixed-detachable hybrid prostheses. J Dent 2016; 49: 22-32.

21. Preciado A, Del Rio J, Lynch CD, Castillo-Oyague R. A new, short, specific questionnaire (QoLIP-10) for evaluating the oral health-related quality of life of implant-retained overdenture and hybrid prosthesis wearers. J Dent 2013; 41: 753-763.
22. Uram-Tuculescu S, Cooper LF, Foegeding EA, Vinyard CJ, De Kok IJ, Essick G. Electromyographic evaluation of masticatory muscles in dentate patients versus conventional and implant-supported fixed and removable denture wearers- a preliminary report comparing model foods. Int J Prosthodont 2015; 28: 79-92.

23. Mahanna FF, Elsyad MA, Mourad SI, Abozaed HW. Satisfaction and Oral Health-Related Quality of Life of Different Attachments Used for Implant-Retained Overdentures in Subjects with Resorbed Mandibles: A Crossover Trial. Int J Oral Maxillofac Implants 2020;35:423-431.

24. von der Gracht I, Derks A, Haselhuhn K, Wolfart S. EMG. correlations of edentulous patients with implant overdentures and fixed dental prostheses compared to conventional complete dentures and dentates: a systematic review and meta-analysis.Clin Oral Implants Res 2017 ; 28: 765-773.

25. Elsyad MA, Hegazy SA, Hammouda NI, Al-Tonbary GY, Habib AA. Chewing efficiency and electromyographic activity of masseter muscle with three designs of implantsupported mandibular overdentures. A cross-over study. Clin Oral Implants Res 2014; 25: 742-748.

26. Feine JS, Maskawi K, de Grandmont P, Donohue WB, Tanguay R, Lund JP. Within-subject comparisons of implant-supported mandibular prostheses: evaluation of masticatory function. J Dent Res 1994; 73: 1646-1656.

27. Elsyad MA, Khairallah AS. Chewing efficiency and maximum bite force with different attachment systems of implant overdentures: a crossover study. Clin Oral Implants Res 2017; 28: 677-682.

28. Cawood JI, Howell RA. A classification of the edentulous jaws. Int J Oral Maxillofac Surg 1988; 17: 232-236.

29. Lekholm U, \& Zarb G. Patient selection and preparation. In: Branemark, P.I., Zarb, G. \& Albrektsson, T., eds. Tissue Integrated Prosthesis:Osseointegration in Clinical Dentistry. Quintessence Publishing Co. Inc. Chicago, IL

30. Drago C. Cantilever Lengths and Anterior-Posterior Spreads of Interim, Acrylic Resin, Full-Arch ScrewRetained Prostheses and Their Relationship to Prosthetic Complications. J Prosthodont 2017; 26: 502-507.

31. ElSyad MA, Ibrahim AE, Nawar NHH, Belal TM. Electromyographic Connectivity of Masseter Muscle with Different Retentive Attachments for Implant Overdentures in Patients with Atrophied Mandibular Ridges: A Crossover Study. Int J Oral Maxillofac Implants 2019; 34: 1213-1222.

32. Schimmel M, Christou P, Miyazaki H, Halazonetis D, Herrmann FR, Muller F. A novel colourimetric technique to 
assess chewing function using two-coloured specimens: Validation and application. J Dent 2015; 43: 955-964.

33. Halazonetis DJ, Schimmel M, Antonarakis GS, Christou P. Novel software for quantitative evaluation and graphical representation of masticatory efficiency. J Oral Rehabil 2013; 40: 329-335.

34. Speksnijder CM, Abbink JH, van der Glas HW, Janssen NG, van der Bilt A. Mixing ability test compared with a comminution test in persons with normal and compromised masticatory performance. Eur J Oral Sci 2009; 117: 580-586.

35. Ferrario VF, Tartaglia GM, Maglione M, Simion M, Sforza C. Neuromuscular coordination of masticatory muscles in subjects with two types of implant-supported prostheses. Clin Oral Implants Res 2004; 15: 219-225.

36. Castroflorio T, Bracco P, Farina D. Surface electromyography in the assessment of jaw elevator muscles. J Oral Rehabil 2008; 35: 638-645.

37. Elsyad MA, Shawky AF. Masticatory function with ball and resilient telescopic anchors of mandibular implantretained overdentures: A crossover study. Quintessence Int 2017; 48: 615-623.

38. Muller K, Morais J, Feine J. Nutritional and anthropometric analysis of edentulous patients wearing implant overdentures or conventional dentures. Braz Dent J 2008; 19: 145-150.

39. Müller F, Hernandez M, Grütter L, Aracil-Kessler L, Weingart D, Schimmel M .Masseter muscle thickness, chewing efficiency and bite force in edentulous patients with fixed and removable implant-supported prostheses: a crosssectional multicenter study.Clin Oral Implants Res 2012; 23:144-150.

40. Zafiropoulos GG, Hoffmann O. Five-year study of implant placement in regenerated bone and rehabilitation with telescopic crown retained dentures: a case report. J Oral Implantol 2009; 35: 303-309.

41. Jacobs R, van Steenberghe D. Masseter muscle fatigue during sustained clenching in subjects with complete dentures, implant-supported prostheses, and natural teeth. J Prosthet Dent 1993; 69: 305-313.

42. De Rossi M, Santos CM, Migliorança R, Regalo SC. All on Four ${ }^{\circledR}$ fixed implant support rehabilitation: a masticatory function study. Clin Implant Dent Relat Res 2014; 16: 594-600.
43. Trulsson M, Francis ST, Bowtell R, McGlone F. Brain activations in response to vibrotactile tooth stimulation: a psychophysical and fMRI study. Journal of neurophysiology 2010; 104: 2257-2265.

44. Yan C, Ye L, Zhen J, Ke L, Gang L. Neuroplasticity of edentulous patients with implant-supported full dentures. Eur J Oral Sci 2008; 116: 387-393.

45. Polzer I, Schimmel M, Muller F, Biffar R. Edentulism as part of the general health problems of elderly adults. Int Dent J 2010; 60: 143-155.

46. Bakke M, Holm B, Gotfredsen K. Masticatory function and patient satisfaction with implant-supported mandibular overdentures: a prospective 5-year study. Int J Prosthodont 2002; 15: 575-581.

47. Fueki K, Kimoto K, Ogawa T, Garrett NR. Effect of implant-supported or retained dentures on masticatory performance: a systematic review. J Prosthet Dent 2007; 98: 470-477.

48. Caloss R, Al-Arab M, Finn RA, Lonergan O, Throckmorton GS. Does long-term use of unstable dentures weaken jaw muscles? J Oral Rehabil 2010; 37: 256-261.

49. Jacobs R, van Steenberghe D, Naert I. Masseter muscle fatigue before and after rehabilitation with implant-supported prostheses. J Prosthet Dent 1995; 73: 284-289.

50. Karkazis HC, Kossioni AE. Surface EMG activity of the masseter muscle in denture wearers during chewing of hard and soft food. J Oral Rehabil 1998; 25: 8-14.

51. Heckmann SM, Heussinger S, Linke JJ, Graef F, Proschel P. Improvement and long-term stability of neuromuscular adaptation in implant-supported overdentures. Clin Oral Implants Res 2009; 20: 1200-1205.

52. Dellavia C, Francetti L, Rosati R, Corbella S, Ferrario VF, Sforza C. Electromyographic assessment of jaw muscles in patients with All-on-Four fixed implant-supported prostheses. J Oral Rehabil 2012; 39: 896-904.

53. Agrawal KR, Lucas PW, Bruce IC, Prinz JF. Food properties that influence neuromuscular activity during human mastication. J Dent Res 1998; 77: 1931-1938.

54. van der Bilt A, Speksnijder CM, de Liz Pocztaruk R, Abbink JH. Digital image processing versus visual assessment of chewed two-colour wax in mixing ability tests. J Oral Rehabil 2012; 39: 11-17. 